\title{
Work in Progress: Flexibility and Professional Preparation via a Multidisci- plinary Engineering Curriculum
}

\section{Dr. Noah Salzman, Boise State University}

Noah Salzman is an Assistant Professor at Boise State University, where he is a member of the Electrical and Computer Engineering Department and IDoTeach, a pre-service STEM teacher preparation program. His work focuses on the transition from pre-college to university engineering programs, how exposure to engineering prior to matriculation affects the experiences of engineering students, and engineering in the K-12 classroom. He has worked as a high school science, mathematics, and engineering and technology teacher, as well as several years of electrical and mechanical engineering design experience as a practicing engineer. He received his Bachelor of Science degree in Engineering from Swarthmore College, his Master's of Education degree from the University of Massachusetts, and a Master's of Science in Mechanical Engineering and Doctorate in Engineering Education from Purdue University.

\section{Dr. Vicki Stieha, Boise State University}

Vicki Stieha, Ph.D. is a faculty member at Boise State University. She earned her doctorate from the University of Cincinnati. Her current work and research focuses on pedagogical and curricular reform in higher education with special attention to increasing the success of underrepresented students.

\section{Dr. Amy J. Moll, Boise State University}

Amy J. Moll is a Professor in the Micron School of Materials Science and Engineering at Boise State University. Moll received her B.S. degree in Ceramic Engineering from University of Illinois, Urbana in 1987. Her M.S. and Ph.D. degrees are in Materials Science and Engineering from University of California at Berkeley in 1992 and 1994. Following graduate school, Moll worked for Hewlett Packard (San Jose, Calif. and Colorado Springs, Colo.). She joined the faculty at Boise State as an Assistant Professor in Mechanical Engineering in August of 2000. Along with Dr. Bill Knowlton, Moll founded the Materials Science and Engineering Program at BSU and served as the first chair. From 2011 to 2017, she wasDean of the College of Engineering. Her research interests include engineering education and microelectronic packaging, particularly 3-D integration and ceramic MEMS devices.

\section{Dr. JoAnn S. Lighty, Boise State University}




\section{Work-in-Progress: Flexibility and Professional Preparation via a Multidisciplinary Engineering Curriculum}

This paper reports on one institution's work-in-progress to build innovation and creativity into a flexible, ABET accredited undergraduate Engineering B.S. degree that provides a variety of choices to undergraduate engineering students. The new Engineering Plus degree has a core set of required foundational courses in engineering, a multi-year design sequence, and allows for self-defined pathways. The new curriculum also offers three defined degree pathways that have been chosen based on an examination of student "fate" data: secondary education, pre-medical, and environmental studies, with additional pathways planned for the near future. The fate analysis examined the paths of students who were enrolled in an engineering or STEM major in one year and samples their major choice in the following year. This analysis maps the flow of students into and out of the major with demographic slicers to more closely understand these inmigration and out-migration choices.

This paper will detail the development of the program and its related research inquiry which includes a qualitative comparison of the students who are drawn to this new approach to engineering.

\section{Introduction}

Engineering as a discipline sits at the volatile intersection of a professional landscape that is rapidly changing and an educational system that is perennially resistant to change. Recent calls for innovation and creativity including "The Moonshot Approach to Change in Higher Education" [1] outline a needs analysis for education in the 21 st century. Industry has stressed the need for college graduates who are comfortable with ambiguity and uncertainty, problem solvers and problem finders, empathetic, bold thinkers, and lifelong learners. Many of these needs have long been part, to varying degrees, of the learning outcomes associated with undergraduate engineering programs. However, limited curricular flexibility and minimal focus on design in the middle years of the curriculum in traditional disciplinary engineering programs reduces the effectiveness of these programs in graduating students equipped to solve $21^{\text {st }}$ century design problems.

Both retaining students and attracting new students to engineering are important. Unlike other STEM degrees, students are less likely to "migrate" into an engineering program [2]. New strategies that attract a more diverse student body are essential. Recent studies have indicated that offering more choice and flexibility will attract women [3], [4]. Variables such as quality of instruction and curriculum, particularly in the lower division years, reduce the likelihood of women leaving engineering programs [5]. Throughout the literature on STEM retention, climate and caring are keys to retention in the first two years of college, particularly for women and underrepresented groups [6].

Various institutions are taking a variety of approaches to transform education and support the development of students prepared to take on "wicked" problems requiring multidisciplinary perspectives. The University of Colorado at Boulder, for example, launched their Engineering Plus program in 2013. CU Boulder is a model of a public institution that is seeking to expand 
student options and increase participation of women and underrepresented minority students through increased flexibility in an engineering degree program [7]. Engineering Plus includes a sequence of design-focused core courses, an emphasis in a traditional engineering discipline, and a variety of "Pluses" that allow students to add an additional concentration in an area that they are passionate about pursuing.

Other institutions are also reshaping their engineering curricula, increasing flexibility and integrating more engineering design. These programs are seeing increased numbers of women and underrepresented minority students majoring in engineering. Stevens Institute of Technology [8] and James Madison University [9] have developed programs incorporating engineering design through all four undergraduate years. Private colleges implementing flexible engineering programs include Olin College of Engineering, Dartmouth College, and Harvey Mudd College. These programs are recognized in the top 5 schools with the highest percentage of their bachelor's degrees awarded to women [10].

The Engineering B.S.E. program offered through the Polytechnic School of Arizona State University's Ira A. Fulton Schools of Engineering incorporates flexibility and multiple design opportunities via an open-access engineering degree program at a large public university. The college ranked $13^{\text {th }}$ of the bachelor's degrees awarded to women by school in 2016 [10]. The University of San Diego is creating a new General Engineering degree designed to integrate engineering and social justice [11]. Each of these programs has its own approach to offering increased flexibility and opening pathways to include disciplines outside of engineering and as they do so we see increasing numbers of women graduating from their programs.

\section{Redesigning curricula to change the outcomes}

Inspired by these institutions, the College of Engineering at Boise State University developed our own novel engineering degree to prepare students for $21^{\text {st }}$ century engineering challenges and attract and retain a more diverse population of engineering students. Recruitment and retention of these students is important to us and important to our regional industry partners who have hundreds of engineering related positions that general engineering students can fill. Our industry advisors are also looking for students who bring diverse skills and experiences into the workplace. Meeting these multiple needs requires greater flexibility in the degree requirements relative to our traditional degrees.

The Engineering Plus program has three major components designed to increase the flexibility of an engineering degree and to support diverse engineering students. The first component of the program is a reduction of the number of required engineering credits while still meeting ABET accreditation requirements. A summary of the curriculum is shown in Table 1, and it includes one year ( 30 credits) of mathematics and science and 1.5 years ( 45 credits) of engineering required for accreditation.

The overall reduction of engineering credits as compared to traditional engineering majors was necessary to allow us to implement the second component of the program--coherent pathways designed to allow students to develop expertise beyond engineering or specific pre-professional preparations. The Teaching Pathway, for example, is designed to allow students to earn both an 
accredited engineering degree and licensure as a mathematics, science, or engineering teacher, while the Pre-medical Pathway will allow students to take all of the coursework required for admission to medical schools. The Environmental Studies Pathway leverages the environmental engineering courses currently offered through civil engineering plus coursework in geosciences, social science, and public policy to strengthen the multidisciplinary curriculum. A business pathway will help students to develop complementary expertise and serve as an alternative route for students considering leaving engineering to pursue degrees in these areas. Self-defined pathways will better accommodate existing minors (e.g. supply chain management, art, psychology, anthropology) outside the college of engineering which will complement the design components in the engineering courses. Our analysis of student data, described in the following section, suggests the new Engineering Plus pathways will be attractive to women and underrepresented minorities who have migrated out of the college in prior years.

Table 1: Overview of Engineering Plus Curriculum

\begin{tabular}{|lc|}
\hline Curriculum & Credits \\
\hline General Education Requirements: & 24 \\
Mathematics and Science: Calculus I, II, \& III, Diff Equations, Statistics, Chemistry, Physics & 32 \\
Engineering Core Courses: Programming, Graphics, Circuits, Statics, Materials & 16 \\
Engineering Design Sequence (Introduction \& Design, I, II, \& III) ENGR 120, 280, 380 \& & 13 \\
480 & 18 \\
Engineering Electives & Total \\
Pathway Electives & $\mathbf{1 2 1}$ \\
\hline
\end{tabular}

The third component of the program is a multidisciplinary design intensive vertical curriculum supported at the 200-level, 300-level, and capstone levels by three newly developed courses focused on engineering design. Grounded in human-centered design and design thinking, these courses will focus on developing the skills necessary to understand users' experiences and identify and develop appropriate solutions for design problems. The addition of these three design courses, along with engineering design activities in our established First-Year Engineering program, introduces a "design spine" in the curriculum that emphasizes problembased learning across all four years of the engineering degree program. While this curriculum supports contemporary students' desire for flexibility and relevance, we are also building instructional practices to increase the cross-cutting skills referenced in the "Moonshot" call. We are being intentional as we develop approaches to design that require students to practice being comfortable with ambiguity, to increase students' empathy, to developing strategies for shared leadership, and other $21^{\text {st }}$ century skills.

These curricular and pedagogical elements of flexibility and community are grounded in selfdetermination theory [12] with its components of competence, autonomy, and relatedness. Each aspect of the theory guides curricular development, pedagogical methods, and outcomes assessment in the design-centered curriculum toward increases in students' intrinsic motivation. Students build competence through developing solutions to increasingly complex engineering 
design problems, autonomy through curricular choice and flexible degree pathways able to accommodate students' personal interests and motivation, and relatedness through a conscientious effort to build community within the program.

The College of Engineering at Boise State University is also carefully designing the curriculum and course elements in ways that increase their attractiveness to women. Cavagnaro explains, "students' first contact with a discipline or area of study can either inspire them to dig deeper, or it can turn them off and reduce the subject to a requirement to be checked off' [1]. Kilgore, et al. redesigned first-year engineering curricula to increase contextual details in design problems and argue women's increased success in these activities suggests an increased likelihood to draw them into and keep them in engineering [13].

We believe these courses will play a critical role in retaining the students we hope to attract to this program by providing opportunities for them to solve problems that are important to them while developing their engineering design skills in each year of their degree. We are implementing this new degree in a very lean fashion with only a half-time program coordinator and by adjusting existing faculty workload as required to develop and teach the new courses. These new design courses will be directly controlled by the Engineering Plus program, which affords us the opportunity to use the courses to build connection and community within the program.

\section{Identifying pathways}

Beyond the design spine and core mathematics, science, and engineering courses, the Engineering Plus launch required a set of potential pathways to model to students how they could blend their interests in a coherent degree. To develop pathways that have potential interest to the students who have been leaving the college, we analyzed data from our institutional student enrollment data system and compared that data with programs mentioned above which have been increasing their effectiveness attracting and graduating women in particular.

In the section that follows we describe the use of fate data. The report aggregates enrollment shifts from year to year guided by the research question, "for students in a given fall semester, where did they end up one year later. We used slicers in the data to identify the academic plans (majors) in the engineering disciplines and identified patterns by student gender and considered their subsequent major.. . While our fate data allows us to examine a wide variety of variables (e.g. transfer status, academic level, academic load, and minority status) given the focus of our current work, we limit our analysis to student enrollment patterns for all students and variations by gender. Proportionally, the attrition from engineering to other areas of the university has been fairly consistent over the last five years (see Figure 1). Therefore, we aggregated the data from first-degree undergraduate students 2012-2016 (excludes non-degree seeking and postbaccalaureate students) and across all five engineering disciplines for this report to avoid the distraction of minor year to year differences. Using descriptive statistics we examined trends and

patterns for one year migration out of engineering into other majors with our primary focus being non-STEM majors that we can now integrate into a program of study through the Engineering Plus program. 
When analyzing enrollment data from the last five years from all engineering majors, female students depart Engineering majors for non-STEM majors or withdraw from the university completely at roughly the same rate. A slightly higher percentage of women than men are retained at the university on the whole and this pattern is also represented in our college's data. Yet, because their enrollment rate is so much smaller than our male students' in our majors, their departure reduces our "critical mass" [14] of women in the college. Examining the patterns of attrition from engineering by gender and reason are important as we build the Engineering Plus program because we can take these reasons into consideration as we develop curriculum and program messaging for students.

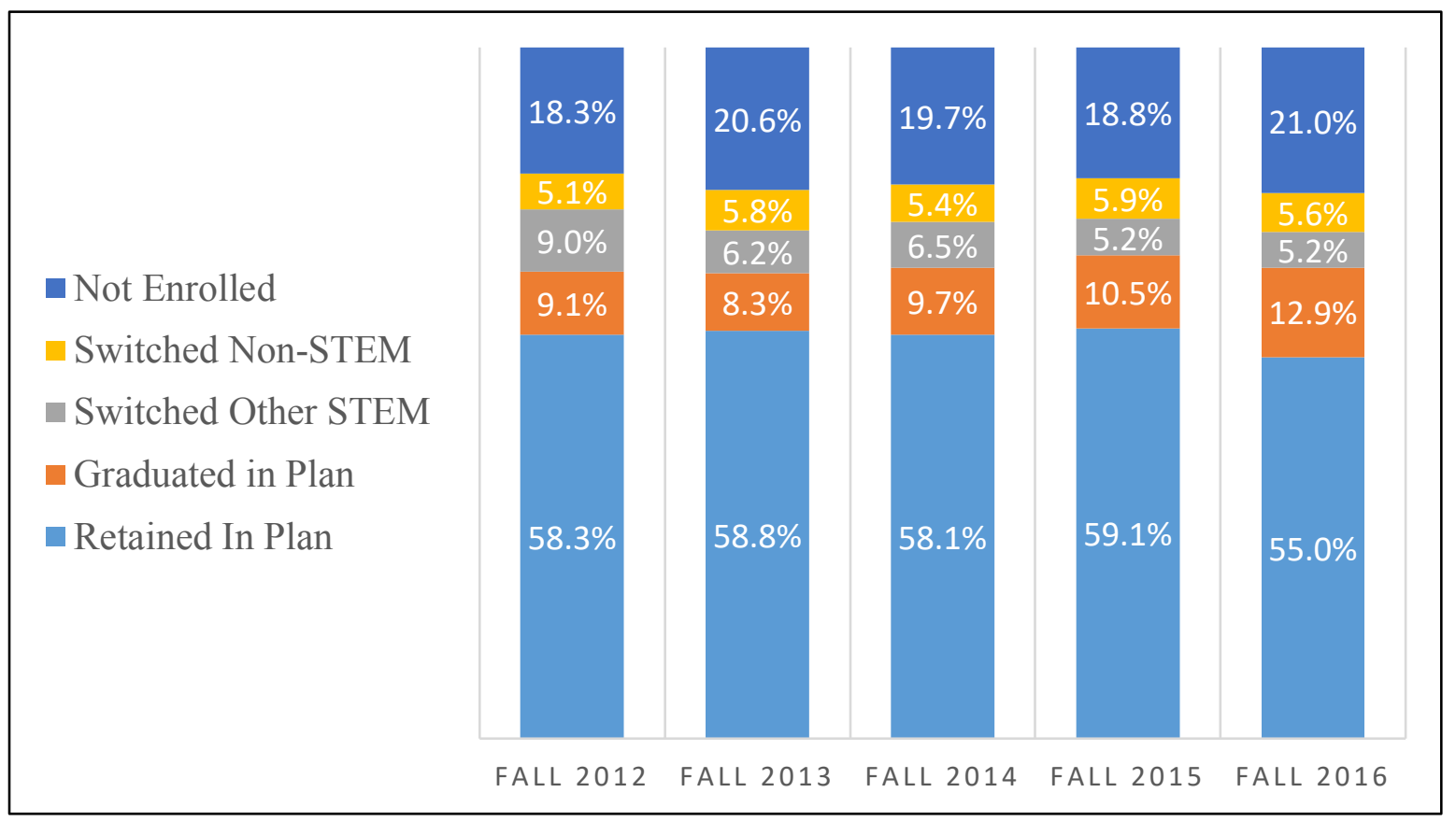

Figure 1: Follows engineering majors recording their "current" major one year hence.

Our fate analysis examined the different majors outside of STEM to which students migrated when they left an engineering degree. By disaggregating these patterns to examine the destination disciplines more closely, we found that the patterns by gender reflect themes identified in the literature for major preferences by gender. Zafar, for example, found that college aged women favored degree programs emphasized social responsibility, a concern for people and the environment [15]. 
Table 2: Analysis of students' academic standing in the year following their departure from engineering

\begin{tabular}{|c|c|c|c|c|}
\hline & \multicolumn{2}{|c|}{ Women } & \multicolumn{2}{|c|}{ Men } \\
\hline & Count & $\%$ & Count & $\%$ \\
\hline Not enrolled & 205 & $16 \%$ & 1733 & $20 \%$ \\
\hline Good Standing Probation & & & & \\
\hline Removed or Reinstated & 28 & $14 \%$ & 286 & $17 \%$ \\
\hline Switched Non Stem & 92 & $7 \%$ & 457 & $5 \%$ \\
\hline Switched STEM & 120 & $9 \%$ & 504 & $6 \%$ \\
\hline Total attrition & 417 & $45 \%$ & 2694 & $48 \%$ \\
\hline Total & 1318 & $100 \%$ & 8499 & $100 \%$ \\
\hline
\end{tabular}

Women who leave engineering at Boise State University migrate to health or medical disciplines (includes health science, nursing, kinesiology, radiologic science, respiratory care, and athletic training) at a higher rate than their male counterparts. For men, however, business is the greatest recipient of engineering's former majors. While men migrate from engineering majors to construction management, that major is not in the top five for women. Accountancy attracts the same percentage of men and women. These gender differences and those shown in Table 3 demonstrate the importance of disaggregating attrition patterns, particularly if a program has an expressed goal to increase the number of women in engineering. As previously described, these data motivated the creation of curricula for a STEM Education pathway, a health/medical pathway, and one for business to allow these students to remain in engineering while developing expertise in an additional area of study.

Table 3: Majors selected by students in the year following their departure from engineering

\begin{tabular}{|c|c|c|c|c|}
\hline Rank & Women & $\%$ & Men & $\%$ \\
\hline 1 & Health/medical & $18 \%$ & Business & $26 \%$ \\
\hline 2 & Accountancy/Finance & $14 \%$ & Construction Management & $15 \%$ \\
\hline 3 & Business & $11 \%$ & Accountancy Finance & $14 \%$ \\
\hline 4 & $\begin{array}{l}\text { Games, Interactive Media, } \\
\text { and Mobile }\end{array}$ & $10 \%$ & Health/Medical & $6 \%$ \\
\hline 5 & Education & $9 \%$ & $\begin{array}{l}\text { Games, Interactive Media } \\
\text { and Mobile }\end{array}$ & $5 \%$ \\
\hline
\end{tabular}

\section{Connecting Fate Data with Initial Pathways}

Above we discussed the pathways that we are developing to share with students. The premedical pathway, for example, will demonstrate to the $18 \%$ of women and $6 \%$ of men who leave that they can remain in engineering and prepare for medical graduate work or careers. Similarly, the education pathway will address those who are departing our college to pursue an education degree. A new Business Bridge to Career combines popular business courses with engineering 
and will help students who are interested in engineering business (including sales and supply chain, which are area of high demand according to our industry partners).

Finally, while the fate data does not directly reflect some of the pathways we have created we are aware that there are students whose interests keep them from ever entering the college. We frequently hear that students who want to study environmental engineering, for example, opt to take courses in our university's social science based environmental studies program. They are not captured in the fate data because they do not ever matriculate in the College of Engineering.

\section{Conclusion}

Informed by fate data exploring the most common majors of students leaving engineering and the literature on other programs that are offering new alternative curricula, we are building a new flexible, design-focused Engineering Plus program with the intent of recruiting and retaining more students, especially women, in engineering. While understanding the patterns of outmigration from engineering is helpful, our intention is to market majors that demonstrate the flexibility of engineering as a core discipline with which other interests can be pursued. If students have a narrow perception of the traditional engineering degrees, they are less likely to see the many possibilities that are open to them with an engineering major. We join other programs experimenting with the curriculum to reduce the number of engineering credit hours, introduce of a project-based design spine, and the creation of a variety of structured curricular pathways aligned to the interests of our students. As more engineering programs diverge from the dominant pattern we can begin to empirically examine the impact of our program design choices and, in time, both close the leaky pipeline of women pursuing engineering degrees as well as increase the migration into the degree.

\section{References}

[1] L. B. Cavagnaro and H. Fasihuddin, "A Moonshot Approach to Change in Higher Education: Creativity, Innovation, and the Redesign of Academia," Lib. Educ., vol. 102, no. 2, 2016.

[2] M. W. Ohland, S. D. Sheppard, G. Lichtenstein, O. Eris, D. Chachra, and R. A. Layton, "Persistence, Engagement, and Migration in Engineering Programs," J. Eng. Educ., 2008.

[3] S. Parikh, H. Chen, K. Donaldson, and S. Sheppard, "Does Major Matter? A Look At What Motivates Engineering Students In Different Majors," presented at the 2009 Annual Conference \& Exposition, 2009, pp. 14.500.1-14.500.13.

[4] L. Dickson, "Race and Gender Differences in College Major Choice," Ann. Am. Acad. Pol. Soc. Sci., vol. 627, no. 1, pp. 108-124, 2010.

[5] E. Litzler and J. Young, "Understanding the Risk of Attrition in Undergraduate Engineering: Results from the Project to Assess Climate in Engineering," J. Eng. Educ., vol. 101, no. 2, pp. 319-345, Apr. 2012.

[6] J. A. Gasiewski, M. K. Eagan, G. A. Garcia, S. Hurtado, and M. J. Chang, "From Gatekeeping to Engagement: A Multicontextual, Mixed Method Study of Student Academic Engagement in Introductory STEM Courses," Res. High. Educ., vol. 53, no. 2, pp. 229-261, 2012. 
[7] M. S. Zarske, J. L. Cunitz, M. H. Forbes, and J. F. Sullivan, "General Engineering Plus: Creating Community in a Flexible yet Technical Engineering Degree," presented at the 2015 ASEE Annual Conference \& Exposition, 2015, pp. 26.816.1-26.816.18.

[8] B. Frank, D. Strong, R. Sellens, and L. Clapham, "Progress with the Professional Spine: A Four-Year Engineering Design and Practice Sequence,” Australas. J. Eng. Educ., Nov. 2015. [9] O. Pierrakos, E. C. Pappas, R. L. Nagel, and J. K. Nagel, "A New Vision for Engineering Design Instruction: On the Innovative Six Course Design Sequence of James Madison University," presented at the 2012 ASEE Annual Conference \& Exposition, 2012, pp. 25.81.1-25.81.19.

[10] B. L. Yoder, "Engineering by the Numbers," ASEE, 2016.

[11] D. A. Chen and G. D. Hoople, "Contextualizing a New General Engineering Curriculum in the Liberal Arts," presented at the 2017 ASEE Annual Conference \& Exposition, 2017.

[12] R. M. Ryan and E. L. Deci, "Self-Determination Theory and the Facilitation of Intrinsic Motivation, Social Development, and Well-Being.," Am. Psychol., vol. 55, no. 1, p. 68, 2000. [13] D. Kilgore, C. J. Atman, K. Yasuhara, T. J. Barker, and A. Morozov, "Considering Context: A Study of First-Year Engineering Students," J. Eng. Educ., vol. 96, no. 4, pp. 321-334, Oct. 2007.

[14] N. Dasgupta, "Ingroup Experts and Peers as Social Vaccines Who Inoculate the SelfConcept: The Stereotype Inoculation Model," Psychol. Inq., vol. 22, no. 4, pp. 231-246, Oct. 2011.

[15] B. Zafar, "College Major Choice and the Gender Gap," J. Hum. Resour., vol. 48, no. 3, pp. 545-595, 2013. 